\title{
PERANCANGAN MEDIA PEMBELAJARAN UNTUK MENUNJANG KEGIATAN BELAJAR SISWA BERBASIS ANDROID
}

\author{
Dewi Driyani $^{1}$, Juliana ${ }^{2}$, Siti Khotijah ${ }^{3}$ \\ Informatika, Universitas Indraprasta PGRI \\ driyani.dewi@gmail.com¹,kallya_des@yahoo.com², sitik2805@gmail.com³
}

\begin{abstract}
Abstrak
Perkembangan teknologi informasi yang sudah semakin pesat terutama kemajuan komunikasi seperti smarphone yang mempunyai teknologi sistem operasi android, dimana android ini bisa memberikan fitur-fitur yang menarik bagi penggunanya, pengguna android bukan saja dari kalangan orang dewasa, kalangan anak-anak juga banyak yang menggunakan android, dimana anak-anak bisa menghabiskan waktu berjam-jam bahkan bisa seharian. Dengan banyak waktu yang dihabiskan oleh anak-anak dalam menngunakan android mengakibatkan ketergantungan terhadap android dan hal tersebut juga dapat menggangu perkembangan anak. Dengan melihat permasalahan tersebut itu maka penulis merancang media pembelajaran dengan memanfatkan kemajuan android dimana tujuan dari penelitian ini bisa membantu kegiatan belajar anak-anak dalam tingkat sekolah khususnya siswa yang berada pada tingkat TKQ atau TPQ dengan memanfaatkan kemajuan android. Metode penelitian yang digunakan adalah waterfall, dimana penelitian ini mempuyai tahap analisa data, design, coding, testing dan implemetasi. Dan program yang digunakan untuk merancang aplikasi yaitu program Appy Pie. Alat yang digunakan untuk merancang media pembelajaran ini diantaranya Unified Modeling Langunge (UML) dan flowchart. Hasil dari penelitian ini adalah aplikasi yang berisi tentang pembelajaran agama islam yang berisi tentang informasi ibadah seperti sholat dan belajar membaca Alquran serta game edukasi yang membahas pembelajaran tentang agama Islam.
\end{abstract}

Kata Kunci : Perancangan, Media, Pembelajaran, Android

\begin{abstract}
The increasingly rapid development of information technology, especially in communication tool, has created smartphones with Android operating system. The android can provide attractive features to users consisting of not only adults, but also children. Children can spend hours, or even all day long to use Android. A lot of time spent by them to use Android, causes dependence on Android, hampering children's development. Considering the problems, the researcher then designs a learning medium by utilizing the development of Android technology with the aim of helping school-aged children, especially students at the $T K Q$ or TPQ level with learning activities by utilizing the android development. The research uses waterfall method, in which the data are analyzed in several stages, namely designing, coding, testing and implementing, The program used to design the application is Appy Pie. The tools used to design the learning medium include Unified Modeling Langunge (UML) and flowcharts. The result of this study is an application that contains Islamic learning explaining information on worship such as prayer, Al-Qur'an recital as well as an educational game discussing Islamic learning.
\end{abstract}

Keywords: Designing, Media, Learning, Android

\section{PENDahuluan}

\section{Latar Belakang}

Perkembangan teknologi yang semakin pesat saat ini memudahkan mehidupan diberbagai pihak. Salah satunya adalah Kemajuan teknologi informasi seperti smartphone dimana smarphone ini merupakan kemajuan teknologi yang paling diminati oleh berbagai pihak karena memberikan berbagai informasi. Dan banyak orang berpendapat smarphone itu selain digunakan untuk handphone, smartphone juga dianggap sebagai komputer mini yang bisa berhubungan 
dengan internet dan memberikan berbagai informasi yang diinginkan. Istilah smarphone tidak akan terlepas dari istilah android karna android merupakan sistem operasi pada smarphone. Android memberikan fitur yang menarik bagi penggunanya. Begitu juga dengan perkembangan dari android yang sudah sangat maju yang membuat era komunikasi yang juga ikut berkembang. Saat ini pengguna android bukan hanya kalangan orang dewasa tetapi pengguna android sudah merambah kepada anak-anak bahkan anak-anak bisa duduk berjam jam bahkan seharian dengan menggunakan android dan hal tersebut bisa berdampak ketergantungan terhadap android dan juga bisa terganggunya perkembangan anak, dimana seharusnya waktu yang digunakan olehanak-anak adalah bermain diluar, bersosialisasi dengan teman-temannya serta belajar.

Dengan melihat permasalah diatas maka penulis memanfaatkan kemajuan android dengan membuat perancangan media pembelajaran untuk siswa untuk menunjang kegiatan belajar khususnya pada siswa tingkat sekolah TKQ atau TPQ, dimana aplikasi ini berbasiskan android. Aplikasi yang dirancang ini ditujukan untuk anakanak dimana aplikasi yang akan dirancang ini membahas pembelajaran agama untuk anak-anak yang berada dalam tingkat belajat TPQ dan TKQ sehingga anak-anak bisa bermain serta belajar sekaligus. Pembuatan aplikasi ini menggunakan aplikasi Appy Pie dimana Appy Pie merupakan salah satu program untuk merancang aplikasi pembelajaran.

Penelitian terdahulu dilakukan oleh Puji Asmaul Chusna dalam judul nya yaitu pengaruh media gadget dalam perkembangan karakter anak, dimana penelitian ini berisi tentang penggunaan gadget pada usia dini yang mengakibatkan terganggunya perkembangan anak dan dari penelitian ini membutuhkan pengawasan dari orang tua dalam mengontol dan mengatur penggunaan gadget pada anak.[4]. Dan hal tersebut memotivasi saya untuk membuat salah satu solusi dengan memanfaatkan android sehingga penggunaan android bisa membantu perkembangan pada anak terutama dalam hal proses belajar.

Dalam proses belajar mengajar diperlukan media pembelajaran yang digunakan untuk memberikan pemahaman kepada para peserta belajar. Media pembelajaran merupakan salah satu alat untuk berkomunikasi dan berinteraksi antara guru dan muridnya. Pengertian Pembelajaran merupakan suatu sistem, yang terdiri dari berbagai komponen yang saling berhubungan satu dengan yang lain [2]. Pengertian pembelajaran adalah suatu kegiatan untuk membuat siswa belajar dengan melibatkan beberapa unsur, baik ekstrinsik maupun intrinsik yang melekat dalam diri siswa dan guru, termaksuk lingkungan, guna tercapainya tujuan belajar - mengajar yang telah ditentukan [3].

Taman pendidikan Al-Quran atau disingkat menjadi TPQ dan taman kanak-kanak AlQuran disingkat TKQ merupakan salah satu lembaga atau kelompok masyarakat yang memberikan pendidikan non formal keagamaan islam dimana pengajaran TKQ atau TPQ diberikan sebelum masuk sekolah dasar.

Android adalah merupakan sistem operasi yang berbasis Linux untuk telepon seluler seperti telepon pintar dan komputer tablet. Android merupakan sistem operasi yang berada dalam smarphone maupun komputer [1]. Sebelumnya android merupakan sistem operasi yang berbasis linux yang dikembangkan langsung oleh Adroid Inc dan kemudian Android dirilis pada tahun 2007 bersamaan dengan berdirinya Open Handset Alliance. 
Appy Pie merupakan salah satu tool untuk membangun dan mengembangkan aplikasi yang berbasis android, windows, dan IOS. Appy Pie ini memudahkan membangun aplikasi tanpa harus mahir dalam suatu bahasa pemograman. Penggunaan Appy Pie tidak perlu mendownload aplikasinya, jadi cukup mengakses Appy pie di web dan menggunakan sistem drag dan drop.

UML merupakan bahasa pemodelan untuk menangkap arsitektur, pelaku dan struktural aspek dari suatu sistem [5]. Uml juga dapat dikatakan salah satu sarana komunikasi antara aplikasi dan pelaku bisnis, dimana UML ini menggambarkan proses perancangan dalam sistem.

Flowchart adalah suatu bagan dengan simbol-simbol tertentu yang menggambarkan urutan proses secara mendetail dan hubungan antara suatu proses (instruksi) dengan proses lainnya dalam suatu program [4].

Tujuan penelitian yaitu dibuat perancangan media pembelajaran untuk menunjang kegiatan belajar siswa khususnya pada tingkat sekolah TPQ atau TKQ yang berbasis android.

Hasil yang didapatkan dari penelitian ini adalah aplikasi yang berisi tentang pembelajaran agama islam untuk siswa khususnya siswa yang berada pada tingkat sekolah TPQ atau TKQ. Dan manfaat yang didapat dengan adanya aplikasi pembelajaran berbasis android yaitu siswa bisa belajar sambil bermain dengan menggunakan android, sehingga mengurangi dampak yang didapatkan dengan penggunaan android pada anak.

\section{METODE PENELITIAN}

Metode penelitian yang digunakan dalam penelitian ini adalah waterfall. Metode penelitian yang di gunakan pada penelitian ini didasarkan pada tujuan penelitian yaitu membuat media pembelajaran berbasis android untuk menunjang kegiatan belajar mengajar untuk siswa TPQ dan TKQ. Tahapan proses penelitiannya adalah sebagai berikut :

1. Pengumpulan Data

Data diperoleh dari studi literature dan survey dari pihak TPQ dan TKQ. Datadata yang dikumpulkan adalah datadata yang diperlukan untuk menunjang aplikasi media pembelajaran berbasis android seperti gambar gerakan shalat, huruf hijaiyah, dan soal- soal latihan untuk anak usia TPQ dan TKQ.

2. Alat dan Bahan

Pada proses pembuatan aplikasi media pembelajaran berbasis android ini di perlukan perangkat keras dan perangkat lunak. Perangkat keras yang di gunakan adalah notebook atau Personal Computer (PC) dengan RAM minimal sebesar 2GB. Perangkat lunak yang digunakan dalam pembuatan aplikasi adalah Apple Pie.

3. Tahapan Penelitian

Tahapan penelitian dalam proses pembuatan aplikasi media pembelajaran berbasis android ini adalah sebagai berikut :

a. Analisa Data

Menganalisa seluruh kebutuhan data yang akan di pakai dalam pembuatan aplikasi.

b. Design

Membuat kerangka tampilan dan interface aplikasi.

c. Coding

Memasukkan Bahasa pemrograman ke dalam interface aplikasi.

d. Testing

Melakukan ujicoba terhadap aplikasi yang sudah dibuat.

e. Implementasi

Aplikasi yang sudah di buat di implementasikan terhadap objek penelitian sehingga diketau manfaat dan kendalanya. 


\section{HASIL DAN PEMBAHASAN}

Perancangan media pembelajaran berbasis android ini melalui beberapa tahapan yaitu perancangan diagram UML (Unified Modelling Language), perancangan Diagram Alir (Flowchart), dan perancangan tampilan aplikasi program.

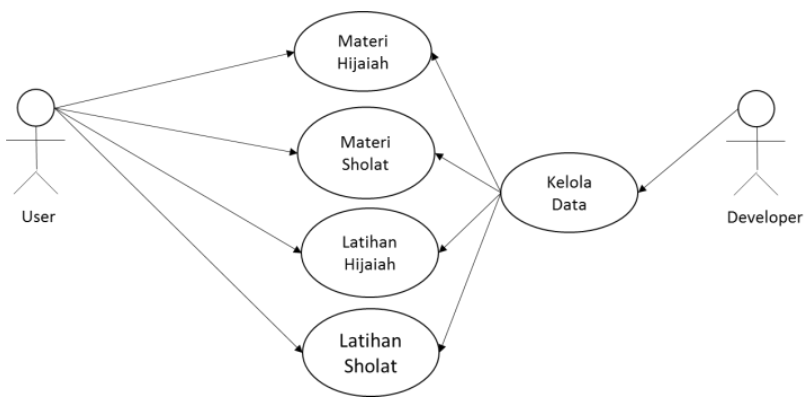

\section{Gambar 1. Unified Modelling Language}

Pada gambar diatas menjelaskan tentang pengguna yang akan menggunakan aplikasi android yang berisi materi hijaiyah, materi sholat, latihan hijaiyah, dan latihan sholat. Materi pada program aplikasi di kelola oleh developer menggunakan software Apple pie.

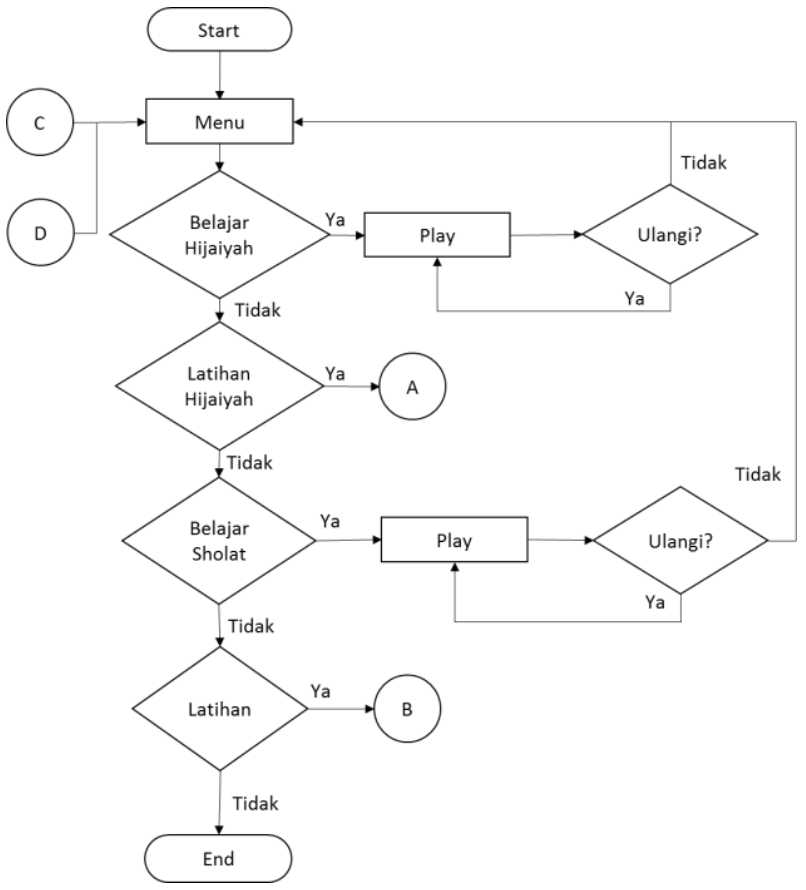

Gambar 2. Flowchart Halaman Utama
Pada gambar 2 diatas menjelaskan bahwa pada halaman utama program akan berisi menu belajar hijaiyah, latihan hijaiyah, belajar shalat, dan latihan. Terdapat menu latihan apabila user telah belajar materi maka user bias mencoba latihan untuk mengadakan evaluasi dari hasil belajar materi.

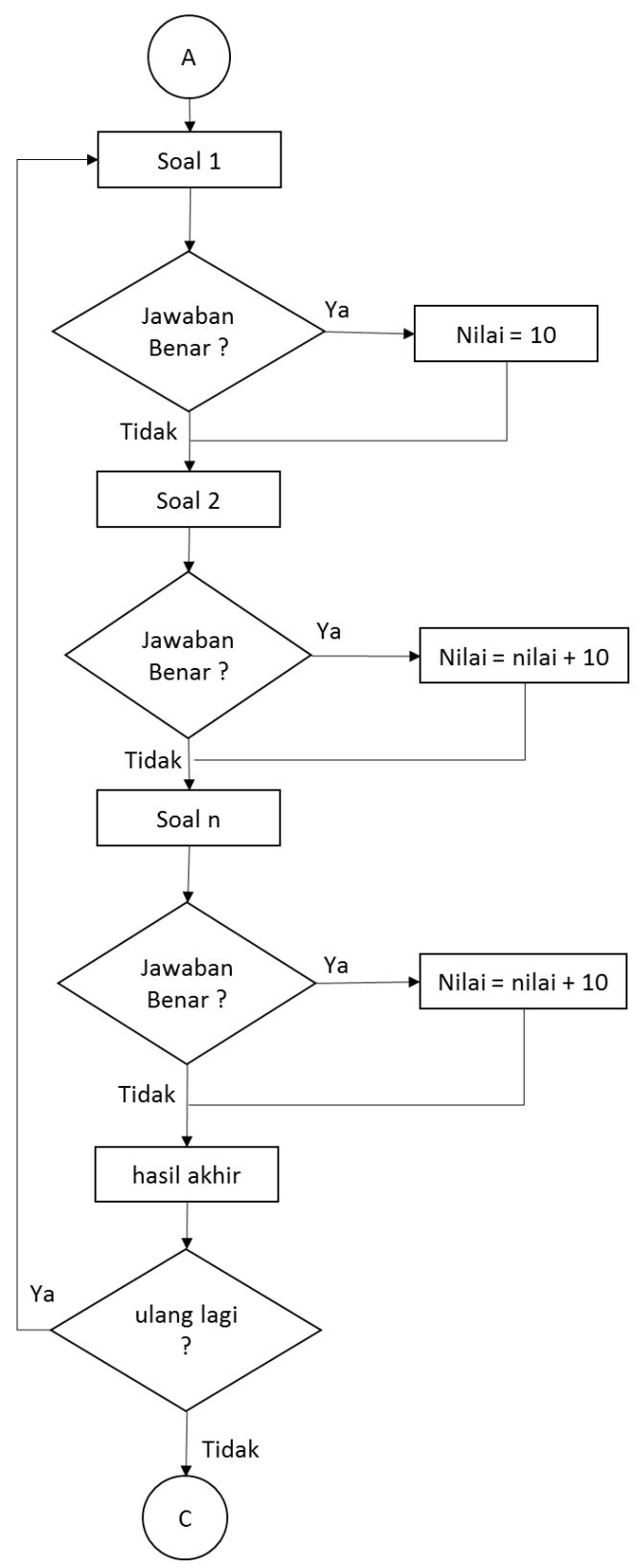

Gambar 3. Flowchart Latihan Hijaiyah

Pada gambar 3 menjelaskan diagram alir latihan hijaiyah. Apabila user menjawab dengan benar makan akan mendapat poin 10. Hasil akhir di dapat dari jumlah nilai 
poin yang didapatkan oleh user. User bisa mengulang ke dalam latihan soal huruf hijaiyah lagi atau berhenti mengerjakan latihan hijaiyah.

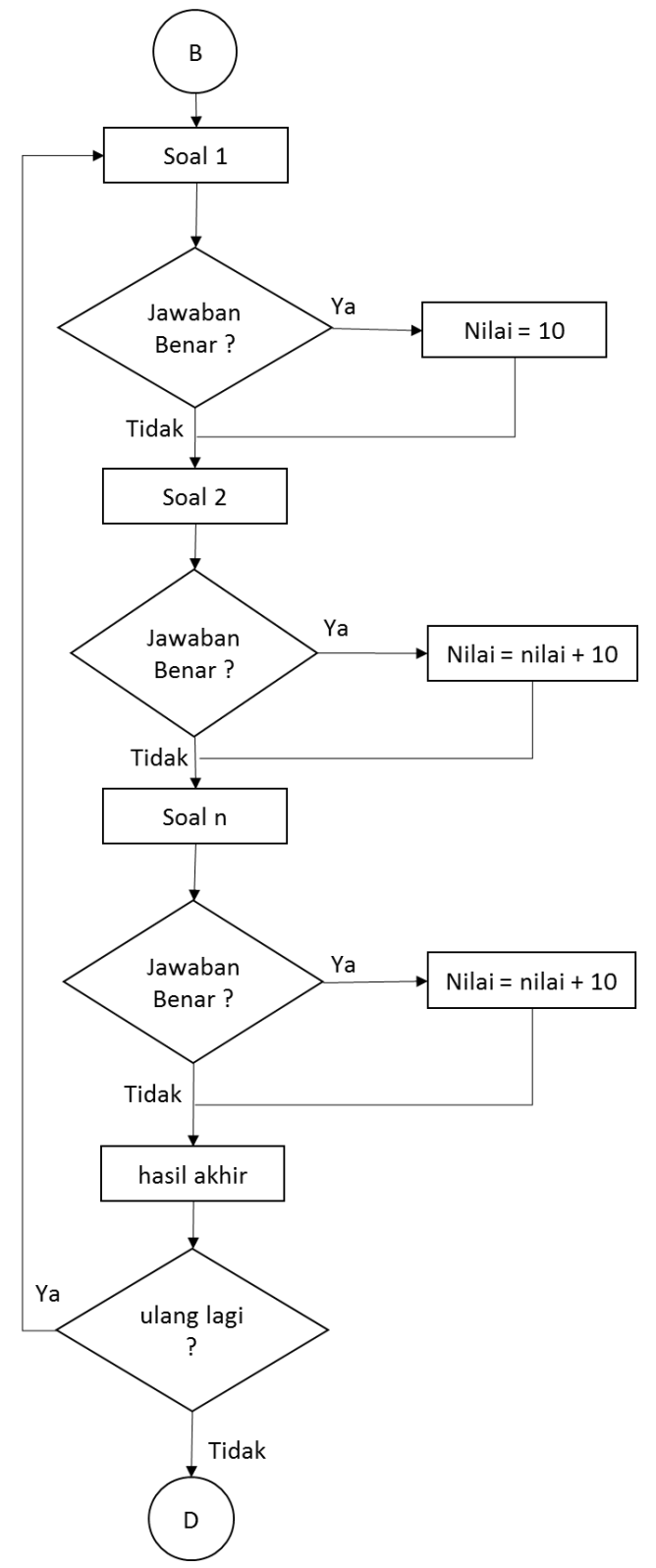

Gambar 4. Flowchart Latihan Sholat

Pada gambar 4 menjelaskan diagram alir latihan sholat. Apabila user menjawab dengan benar maka mendap[atkan poin 10 . Hasil akhir di dapat dari jumlah nilai poin yang didapatkan oleh user. Apabila user ingin mengerjakan soal latihan sholat, user bisa kembali mengulang soal latihan. Atau user bisa berhenti mengerjakan soal latihan.

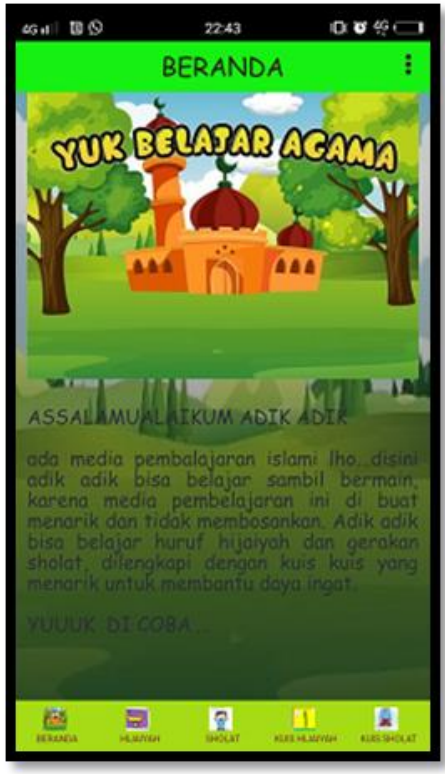

Gambar 5. Halaman Utama

Gambar 5 merupakan halaman awal untuk aplikasi, didalamnya terdapat keterangan dari isi yang akan digunakan. Dan dibagian bawah terdapat menu pilihan yang akan digunakan beranda, hijaiyah, sholat kuis hijaiyah, dan kuis sholat.

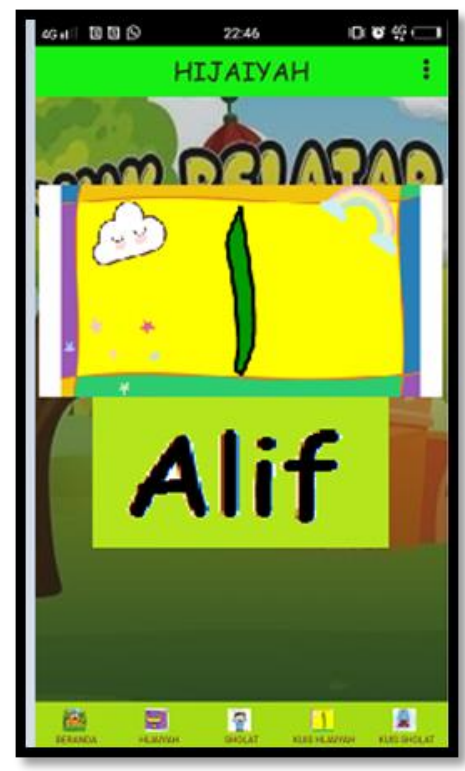

Gambar 6. Tampilan Menu Hijaiyah

Gambar diatas adalah pilihan dari menu hijaiyah. Menu hijaiyah berisikan tentang pembelajaran belajar huruf hijaiyah, dilengkapi dengan huruf hijaiyah dan huruf 
latin untuk memudahkan dalam membaca hijaiyah.

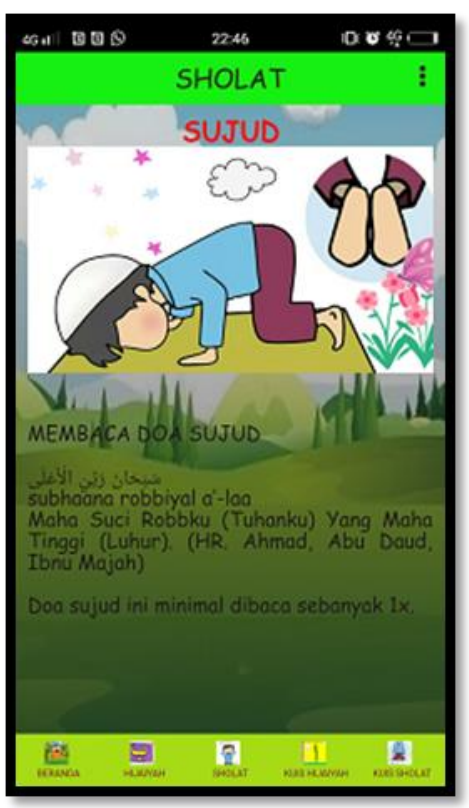

\section{Gambar 7. Tampilan Menu Sholat}

Gambar di atas dari menu sholat, berisi tentang panduan sholat lengkap. Menu sholat dilengkapi dengan gambar gerakan sholat bacaan sholat, dan arti dari bacaan sholat.

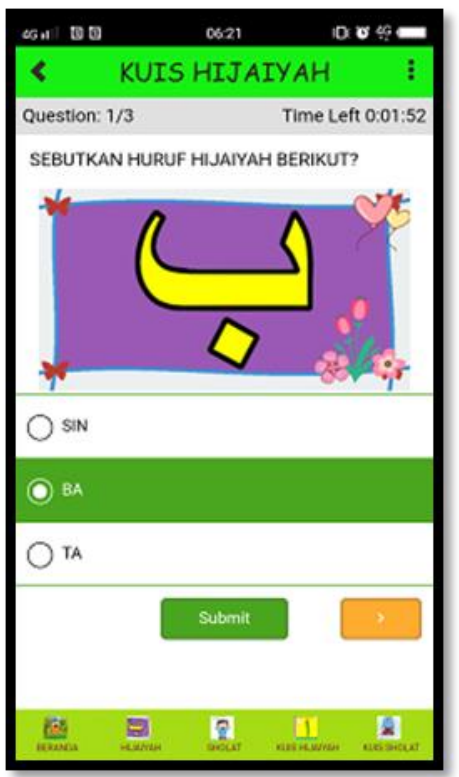

Gambar 8. Tampilan Kuis Hijaiyah
Gambar 8 di atas menjelaskan pada menu kuis hijaiyah, kuis hijaiyah terdiri dari nomor latihan, soal, jawaban, waktu pengerjaan. Jika latihan sudah dikerjakan tekan tombol submit untuk menyimpan jawaban dan tekan tombol panah untuk ke latihan berikutnya.

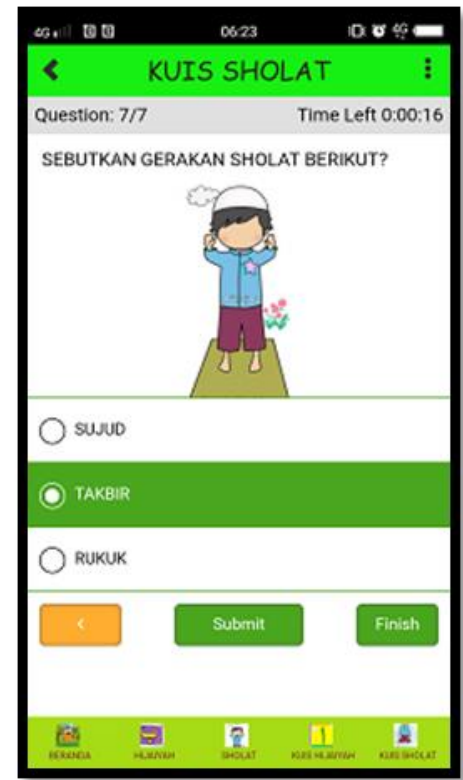

\section{Gambar 9. Tampilan Kuis Sholat}

Gambar 9 menjelaskan tentang aplikasi pada menu kuis sholat. Isi dari halaman kuis sholat adalah pilihan berganda yang terdiri dari nomor, waktu dalam mengerjakan latihan, soal dengan gambar gerakan sholat, pilihan jawaban. Jawaban akan di simpan dengan menekan tombol submit. Panah kanan untuk kembali melihat latihan jika ingin merubah jawaban dapat kembali dan selesai tekan tombol finish. 


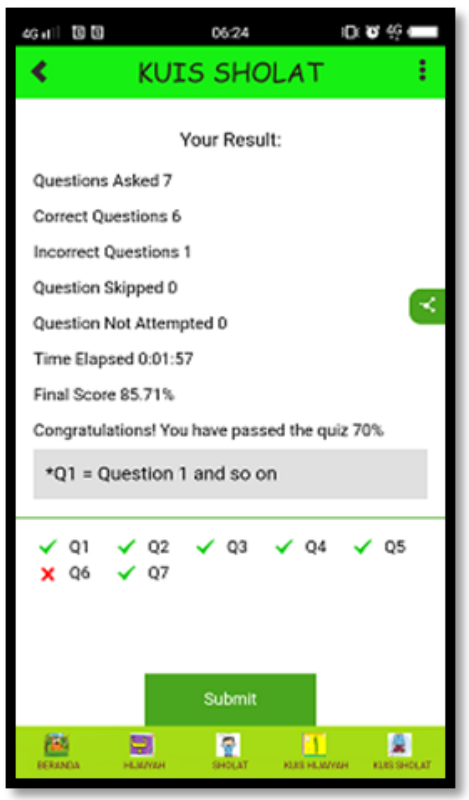

Gambar 10. Tampilan Hasil Akhir

Aplikasi kuis sholat jika sudah selesai dikerjakan akan menampilkan hasil akhir berupa nilai. Dapat dilihat dari gambar aplikasi ini memberikan informasi berupa jumlah pertanyaan, jawaban yang benar, jawaban yang salah, pertanyaan yang tidak dijawab, waktu dalam mengerjakan,dan nilai akhir. Jika ingin melanjutkan latihan, dapat menekan tombol submit.

\section{SIMPULAN}

Simpulan yang di dapat dari perancangan media pembelajaran berbasis android ini adalah :

1. Aplikasi pembelajaran berbasis android ini sangat mudah untuk di gunakan oleh anak- anak usia TPQ dan TKQ.

2. Aplikasi pembelajaran berbasis android ini berisi latrihan kuis yang bisa menambah wawasan anak tentang belajar huruf hijaiyah dan belajar sholat.

3. Aplikasi yang dibuat ini menampilkan gambar- gambar yang menarik dan menyenangkan bagi anak- anak usia TPQ dan TKQ sehingga untuk belajar huruf hijaiyah dan gerakan sholat menajdi kegiatan yang menyenangkan bagi anak- anak.

\section{DAFTAR PUSTAKA}

[1] Safaat H, Nasrudin. Pemrograman Aplikasi Mobile Smarthphone dan Tablet PC Berbasis Android. Bandung: Informatika.2011.

[2]

Rusman. Model-model

Pembelajaran Mengembangkan Profesional Guru edisi kedua. Jakarta : PT. Rajagrafindo Persada. 2014.

[3] Prasetowo, A. Pengembangan Bahan Ajar Tematik. Jogjakarta : Diva Pers. 2013

[4] Puji Asmaul Chusna. Pengaruh Media Gadget Pada Karakter Anak. Jurnal Dinamika Penelitian, Vol. 17, No. 2, ISSN. 1412-2669 November 2017.

[5] Sumalanta,V. M. UML Based Automated Test Case Generation Technique Using Activy Diagram. The Journal Of Computer Science \& Application, Vol. 1, No.9. 2012. 